\title{
LA FUNCIÓN ECONÓMICA DE LA COOPERATIVA Y LA NECESIDAD DE UNA LEGISLACIÓN ADECUADA
}

\author{
POR \\ Enrique GADEA SOLER ${ }^{1}$
}

\section{RESUMEN}

El objetivo de este trabajo es doble: por una parte, se analiza el origen histórico y la función económica actual de las sociedades cooperativas y, por otra, se realiza un estudio crítico de su normativa aplicable, con el objeto de determinar las bases de su futura legislación.

Palabras clave: Cooperativas, su función económica y bases para una futura legislación.

Claves Econlit: K200

\section{COOPERATIVES ECONOMIC PURPOSE AND SUITABLE LEGISLATION}

\begin{abstract}
This paper has dual objectives: it aims to analyse the historical origin and current economic purpose of cooperative companies while also making a critical study of applicable regulations with a view to defining the bases of future legislation.
\end{abstract}

Keywords: Cooperatives, their economic purpose and suitable legislation.

\footnotetext{
${ }^{1}$ Universidad de Deusto. Dirección de correo electrónico: egadea@ der.deusto.es

REVESCO No 108 - Segundo Cuatrimestre 2012 - ISSN: 1885-8031 - www.ucm.es/info/revesco

DOI: 10.5209/rev_REVE.2012.v18.39593

Fecha de recepción: 08/01/2012

Fecha de aceptación: 22/02/2012
} 


\section{ORIGEN Y FUNCIÓN ECONÓMICA ACTUAL DE LAS SOCIEDADES COOPERATIVAS}

El movimiento cooperativo moderno, que debe situarse en la segunda mitad del siglo XIX, nace como reacción de las clases trabajadoras frente a los excesos del sistema capitalista propio de la época y con el objetivo de corregir primero y superar después, a través de la cooperativización de la economía y la sociedad, el sistema capitalista (Llobregat, 1990, p. 4; la utopía de la cooperación tiene su más amplia representación en C. Gide y la Escuela de Nimes: sobre el tema, Lambert, 1970, p. 121 y Drimer, A. y B., 1981, p. 267). Más tarde, las concesiones integrales que atrajeron a tan ilustres cooperativistas, han dado paso a visiones más realistas, hasta el punto que, en la actualidad, la cooperativa, en determinados países, constituye una de las alternativas para la actuación en el marco de un sistema de economía privada. Sin embargo, nos referimos únicamente a determinados países porque a la hora de ofrecer un concepto de cooperativa nos encontramos también con un condicionante geográfico. Es cierto que los principios cooperativos pretenden poner de relieve la coincidencia sustancial del fenómeno cooperativo con independencia del ámbito territorial donde tenga lugar (a saber: lo que caracteriza al fenómeno cooperativo es el objetivo de satisfacer necesidades a través de una empresa de propiedad conjunta y gestión democrática), pero no lo es menos que el papel que desempeñan las cooperativas dista mucho de ser coincidente: en los países menos desarrollados, prevalece la función de reacción respecto a los desequilibrios del sistema (en este ámbito, la cooperativa está destinada, en muchas ocasiones, a ser sólo un correctivo marginal de éste), mientras que, en los países europeos toma mayor protagonismo la orientación posibilista, que, si bien no excluye las funciones originarias, tiene muy presente el fortalecimiento y la adecuada articulación del fenómeno cooperativista, destinado no a cambiar el sistema o a sustituirlo, según ciertas concepciones de los utopistas de la cooperación económica, sino a encomendarle una función integradora en el mismo (Verrucoli, 1965, p. 102).

En España, hasta fecha relativamente reciente ha sido mayoritaria la postura (recogida en la Exposición de Motivos del Código de Comercio) que ha defendido que un presunto principio mutualista impedía a la cooperativa prestar sus servicios a los no socios (por todos, y desde un prisma jurídico, Garrido de Palma, 1981, p. 20). Sin embargo, esa postura no encaja en el planteamiento de los Pioneros de Rochadle, experiencia asociativa que se considera el punto de arranque de la cooperación en sentido estricto, y que en este punto, como 
en tantos otros, fue eminentemente realista. El artículo 1 de los estatutos originarios de la Rochdale Society of Equitable Pioneers de 1844 establece que: «La sociedad tiene por fines y como planes tomar medidas con vistas al interés pecuniario y al mejoramiento de las condiciones sociales y familiares de sus miembros...»; y el artículo 11, aprobado por la Asamblea General de 23 de octubre de 1854, contempla la posibilidad de venta a los no miembros, al señalar que: «Los beneficios realizados para la provisión de mercancías a personas no miembros se dedicarán a la reducción (del valor) de las mercancías en existencia» (un comentario sobre el precepto, puede verse en Holyoake, 1973, p. 43). Ni tampoco puede decirse que se encuentra recogida en los principios cooperativos. Solo en la documentación del XIV Congreso de la ACI, celebrado en Londres en 1934, se prescribía como hipotético principio la venta exclusiva a los socios. Pero ya en el XV Congreso de París de la ACI de 1937, en que se realiza la primera formulación oficial de los principios, no se hace mención a ese principio entre los específicos del movimiento cooperativo, como tampoco aparece en la última versión (a la que nos referiremos en el apartado siguiente) reelaborada por la ACI en el Congreso XXXI, celebrado en Manchester, para conmemorar el centenario de la Alianza. En la actualidad, debe ser aceptado que la utopía de las empresas cooperativas sólo adquiriría verdadera entidad y podría ser plenamente vinculante en un sistema económico cooperativo (Verrucoli, 1958, p. 101). En una economía de mercado se consideran inviables las posturas que no admiten la realización de operaciones con terceros por considerarlas incompatibles con lo que consideran el fin principal de la entidad: la supresión del lucro (en sentido sociológico, de beneficios que van al capital) de la intermediación (Lucas Fernández, 1973, p. 12). Hoy no puede justificarse que la actividad de la cooperativa haya estado acotada por unos límites tan estrechos en relación con las sociedades capitalistas, y más, teniendo en cuenta que el artículo 129.2 de la Constitución Española, cuando se refiere a estas entidades, no impone contenidos, pautas, ni condiciones de estricta observancia al legislador ordinario. Las cooperativas, al igual que las demás empresas, actúan o pueden actuar en el mercado para el cumplimiento de sus fines. En este sentido, puede decirse que no estamos ante una sociedad necesariamente mutualista (en el sentido de no poder realizar prestaciones en relación con el objeto social más que entre los socios y la sociedad) sino ante un tipo societario de configuración (interna) distinta que opera, como los demás, en beneficio de sus propios socios (Verrucoli, 1958, p. 104) y que, por tanto, debe extraer (o, por lo menos, deben tener la posibilidad de extraer, si así lo deciden sus socios) la máxima utilidad de las estructuras organizativas de la entidad. Por ello, no solo es inadmisible no permitir que las cooperativas realicen operaciones con terceros (en base al principio de adhesión voluntaria y abierta, los terceros, si lo desean, tienen expedito el camino 
para ingresar en cualquier momento en la esfera societaria y con ello satisfacer sus intereses y necesidades como socios: Vivante, 1932, p. 323), sino también limitar el volumen de estas operaciones (como todavía, en la actualidad, podemos observar en la legislación española: sobre el tema, Vargas Vasserot, 2006, pp. 199 y ss.).

Para conseguir la eficiencia del sistema cooperativo es necesario que las propias cooperativas constituyan estructuras participativas en la que sus miembros vean satisfechas sus necesidades y reflejadas sus visiones. La especial estructura participativa de las cooperativas se vertebra en torno a tres pilares:

1. El papel del socio. En la cooperativa, los socios participan no sólo aportando las sumas de capital necesarias sino operando como clientes, en las cooperativas de consumo, y como trabajadores, en las cooperativas de producción. Es indudable que esa doble posición de sus miembros constituye una característica propia (aunque no exclusiva: se da también, por ejemplo, en las mutuas de seguros o en las sociedades de garantía reciproca) de las cooperativas, que tiene trascendencia en el plano legal $y$, especialmente, en la configuración del estatus jurídico del socio, al que, por ejemplo, se le reconoce el derecho y se le impone el deber de participar en la actividad cooperativa.

2. La gestión democrática por parte de sus miembros, basada en la asociación igualitaria, que, en la práctica, se concreta, por lo menos en las cooperativas de primer grado, en la regla general de que los socios tengan iguales derechos de voto (un socio, un voto).

3. El sistema de distribución de beneficios, al margen de la contribución en el capital, en proporción a las operaciones, servicios o actividades realizadas por cada socio en la entidad.

A nuestro juicio, el hecho que justifica la especificidad de la sociedad cooperativa no es la gestión preferentemente mutualistica: el elemento definitorio de la cooperativa es que constituye una iniciativa empresarial por parte de un grupo de personas que, al margen de la participación capitalista de cada socio, tiene por finalidad la satisfacción de sus necesidades mediante la recuperación de la forma de empresa personalista y de funcionamiento interno democrático. Ese es el hecho diferencial sobre el que debe basarse la particular consideración y el adecuado tratamiento (incluso en el plano fiscal) para la entidad asociativa cooperativa.

Como se desprende del artículo 129.2 de la Constitución Española, la cooperativa se presenta como una fórmula jurídica adecuada para facilitar el acceso de los trabajadores a la 
propiedad de los medidos de producción y para canalizar las formas participativas en las empresas (Gadea, 1999, p. 193). Concretamente, el artículo 129.2 de la CE establece que «los poderes públicos promoverán eficazmente las diversas formas de participación en la empresa y fomentarán, mediante una legislación adecuada, las sociedades cooperativas». Este precepto constituye un mandato dirigido a los poderes públicos para que éstos fomenten las sociedades cooperativas, es decir, deben tomar las medidas adecuadas para que el modelo económico constitucional de economía social de mercado se nutra de empresarios cooperativos. Con ello, la Constitución Española de 1978 sitúa a la sociedad cooperativa, adecuándose para ello a las exigencias actuales y recogiendo las tendencias más modernas de las Legislaciones europeas sobre cooperación, en el contexto adecuado de la participación, contrastando así con otras Constituciones, como la italiana de 1947, que en su artículo 45 adopta la postura clásica, más restrictiva y parcialmente superada en relación con el Cooperativismo, al señalar que «La República reconoce la función social de la cooperación con carácter de mutualidad y sin fines de especulación privada ...» (en Italia, las formulaciones doctrinales que se posicionan a favor o en contra de que la esencia de la cooperativa descanse o no sobre el fin mutualista son muy numerosas: a favor se han pronunciado Ascarelli, y Oppo; en contra, Ferri o Verrucolli. Una amplia referencia a la cuestión, puede verse en Paniagua, 1997, pp. 338 y ss.).

Por tanto, lo relevante es que la cooperativa constituye el modelo de empresa participativa, que basa su funcionamiento interno en principios de verdadera democracia económica. Sobre la base de esa consideración, en el presente trabajo, vamos a abogar por un modelo de cooperativa, ajena a las restricciones del pasado, abierto, atractivo (desde el punto de vista de sus utilidades) y acorde con los nuevos tiempos. Estamos ante una fórmula jurídica para la organización económica, sujeta a los principios y fines que le son específicos, que tiene (debe tener) la misma extensión técnica y económica que una sociedad capitalista (anónima o limitada) (Divar, 1985, p. 43). De lo contrario, el modelo cooperativo quedará condenado a la condición de marginal, en beneficio de las opciones verdaderamente capitalistas. Este planteamiento es, además, coherente con el principio constitucional de libertad de empresa recogido en el artículo 38 de la Constitución Española, que, en lo que concierne a este punto, comporta el derecho a que los ciudadanos adopten la organización empresarial que deseen. 


\section{VISIÓN CRÍTICA DE LA LEGISLACIÓN SOBRE COOPERATIVAS EN ESPAÑA}

\subsection{La Legislación Republicana de Cooperativas}

La Ley de 9 de septiembre de 1931 y el Reglamento de 20 de octubre del mismo año reconocen, por primera vez, el tipo cooperativista como figura autónoma dentro del marco de los fenómenos societarios y asociativos de contenido económico. La creación de este tipo societario se considera fundamental para identificar la verdadera cooperación. Como señala la Exposición de Motivos de la Ley: «es inaplazable dotar a las cooperativas de un régimen jurídico propio [...] para distinguir la cooperación genuina de la mixtificada o de la simulada». De esta manera, la entidad que se aparta de la normativa legal, receptora de los postulados cooperativistas, es sancionada con la descalificación, es decir, es obligada a abandonar la forma de sociedad cooperativa.

El problema es que el legislador confunde la finalidad de la entidad con la necesidad de organización de la misma, es decir, consolida el alejamiento del régimen jurídico de las cooperativas y de las sociedades mercantiles por su connotación capitalista, sin reparar en las consecuencias prácticas (Gadea, 1994, p. 138). Desde el punto de vista jurídico, se ha criticado la inoperatividad de la entidad que deriva de que la Ley no delimita las facultades de cada órgano social: por ello, la llevanza ordinaria de la entidad por el órgano de administración deviene en imposible, ya que tendrá que acudir en consulta permanente a la asamblea, lo que procura un cooperativismo asambleario y populista nada operativo y poco práctico (Divar, 1985, p. 19); y, también, el deficiente tratamiento del régimen económico, donde no se establece medida alguna en favor de la solvencia de la entidad ni en garantía de los terceros.

\subsection{El Cooperativismo sindical: La Ley de 1942 y su Reglamento de desarrollo}

El 2 de enero de 1942 se aprobó una nueva Ley de Cooperativas y el 11 de noviembre de 1943 se promulgó su Reglamento. Se trata de una Ley eminentemente política y de adaptación del régimen cooperativo a la nueva realidad sindical española. Ello explica que la Ley no adopte cambios radicales con respecto a la de 1931 en lo relativo a la organización y régimen interno de la sociedad cooperativa. Las variaciones derivan del nuevo encuadramiento de la sociedad cooperativa en sus relaciones con el Estado y con la organización sindical, de la 
creación de la Obra Sindical de Cooperación como órgano de patronato y tutela del movimiento cooperativo y de la disciplina político- sindical del mismo (Polo, 1942, p. 220.), así como del sentido que se da a la uniones de cooperativas (cuyos fines son, preferentemente, sociales y sólo, excepcionalmente, económico-cooperativos: Vicent Chuliá, 1979, p. 527.).

Estas circunstancias originan una notable distorsión en el régimen jurídico de la sociedad. Los mayores defectos de esta regulación se originan por la concesión a la jerarquización y dependencia política el máximo valor, olvidando los aspectos jurídicos y técnicos (en especial, el régimen económico está lleno de lagunas y limitaciones) de la cooperativa (Soldevilla, 1973, p. 437). Además, en su articulado se establece una interpretación muy rigurosa del principio mutualista (arts. 41, 42, 43 y 44), por lo que no debe extrañarnos que se señalase que, publicada la nueva Ley de 2 de enero de 1942 que se considerase que la norma parecía dictada para entidades raquíticas y sin aliento; para entidades incapaces para luchar con eficacia en un mercado concurrencial y que sólo pretendían ser solución ínfima para gentes de economía débil (Del Arco, 1972, p. 9).

\subsection{La adaptación del Régimen Jurídico de las Cooperativas a las nuevas exigencias: La Ley General de Cooperativas de 1974}

En la Asamblea Nacional de Cooperativas de 1961 se pone de manifiesto el desfase, cada vez más acusado, entre la realidad y la norma legal y se aprueban las nuevas bases que deben presidir la nueva ordenación legal del cooperativismo. Desde la celebración de aquella se redactaron varios Proyectos de Ley, aunque finalmente, de forma provisional y hasta que se elaborase la nueva Ley, se aprueba el Reglamento de cooperación de 13 de agosto de 1971. Esta solución fue criticada por la doctrina que venía solicitando una profunda reforma, que, como es obvio, no podía ser acometida por un mero cambio de Reglamento por muy audaz y avanzado que fuese éste. Sin embargo, con el nuevo Reglamento, y a pesar de las limitaciones de su rango, se inicia un importante cambio de orientación dentro del cooperativismo español. Se plantean como razones principales de la reforma la necesidad de conseguir empresas más eficaces y competitivas y de atenuar los controles externos que, sobre los órganos de la cooperativa, ejerce la organización sindical.

En la Ley de 19 de diciembre de 1974 y el Reglamento de 16 de noviembre de 1978, aprobado ya en el nuevo contexto democrático, se aprecia una voluntad manifiesta de 
abandonar la concepción restrictiva del Cooperativismo para adoptar una más amplia. Es significativo en este sentido el artículo 1 de la Ley que establece que a través de la formula cooperativa podrá realizarse «cualquier actividad económico-social lícita». Estos nuevos propósitos exigen la construcción de «una institución rigurosa en sus planteamientos sociales y, a la vez, tecnificada, permeable a la especialización y sensible al mercado» (Exposición de Motivos de la Ley). Si la sociedad cooperativa debe comportarse en sus relaciones externas como un comerciante más, debe atribuírsele un régimen jurídico adecuado para la protección del tráfico jurídico y de los derechos de los terceros. No debe extrañarnos, por tanto, que a la hora de realizar una valoración de conjunto de la nueva Ley se señale que es manifiesta la influencia de la normativa de la sociedad anónima: la sociedad mantiene sus principios, y además se beneficia de una tecnificación mayor y se aprovecha de la experiencia de la regulación de la organización societaria anónima. En definitiva, la Ley consigue tecnificar más las cooperativas, compatibilizar sus principios tradicionales con un reforzamiento de su aspecto empresarial, de sus posibilidades de financiación y de una gestión eficaz (Sánchez Calero, 1975, pp. 495 y 513).

De forma resumida, señalar que las principales novedades de la Ley son las siguientes: sobre la constitución, se establece la obligatoriedad de escritura pública, de inscripción en el Registro de cooperativas (al que se confiere carácter jurídico) y de toma de razón en el Registro mercantil; en el plano organizativo, aunque mantiene una terminología diferenciada, el modelo corresponde exactamente al de la LSA: Asamblea General (Junta general), Consejo Rector (Consejo de administración) e Interventores (Censores de cuentas); en relación con el régimen económico, lo más importante es que la Ley vela por su correcta constitución (en este sentido el artículo 13.2 señala que deberá estar desembolsado, al menos, en un veinticinco por ciento en el momento constitutivo y el resto en un plazo no superior a cuatro años) y porque la cooperativa no se desprenda injustificadamente de su patrimonio hasta dejarlo por debajo de la cifra de capital. A la hora de establecer un régimen de protección en garantía de terceros se comentó la dificultad de implantar un sistema adecuado en una sociedad de capital variable. No obstante, el Reglamento de 1978 adopta una solución positiva, aunque no original, en cuanto que reproduce (art. 35) el régimen de la SA (arts. 97 a 99), de manera que salvo que tenga por finalidad compensar pérdidas, será nula toda restitución de aportaciones al capital social que se realice antes de transcurrir el plazo de tres meses o a pesar de la oposición entablada en tiempo y forma por cualquier acreedor. Además, el mencionado carácter de sociedad de capital variable, en virtud del principio de puerta abierta (que en el plano que ahora nos interesa destacar implica 
que los socios cuando lo deseen pueden salir o darse de baja de la cooperativa) exige la adopción de medidas particulares para asegurar la viabilidad de la sociedad y para preservar los derechos de los terceros. Por eso, la Ley permite que los estatutos puedan exigir la permanencia por tiempo determinado en la cooperativa que no podrá ser superior a diez años (art. 11.1), así como establecer un plazo de preaviso, a observar por el socio que cause baja en la cooperativa que no podrá ser inferior a dos meses ni superior a un año (art. 11.1); se conceda a la cooperativa un plazo para el reembolso de hasta cinco años a partir de la fecha de la baja, con derecho, durante este tiempo, a percibir por parte del socio un interés que no será en ningún caso inferior al tipo de interés básico del Banco de España incrementado en dos puntos (art. 11.4) y se adopte la misma regla que rige en Francia, con carácter general, para las sociedades de capital variable (art. 52 de la Ley francesa de 24 de Julio de 1867), es decir, que el socio que se separe responde por el importe que le ha sido reembolsado, y durante un plazo de cinco años, de las deudas contraídas por la sociedad con anterioridad a la fecha de reembolso, en el caso de que el patrimonio social sea insuficiente para hacer frente a ellas (art. 11.5); por último, anotar que se prevé la aplicación del Derecho concursal mercantil.

\subsection{La regulación actual de las Sociedades Cooperativas}

\subsubsection{La competencia legislativa en materia de cooperativas después de la Constitución de 1978}

En la actualidad en España no existe una única Ley sino varias Leyes de cooperativas, dado que la mayoría de las Comunidades Autónomas (CAAA) tienen norma propia. Para explicar esta situación debe tomarse como punto de partida la nueva organización territorial del Estado creada por la Constitución de 1978: se trata de un sistema de organización territorial autóctono, llamado Estado de las Autonomías, que presenta similitudes con un Estado federal, aunque también no pocas diferencias. Con él, se divide España en diecisiete CCAA, distribuyéndose las competencias entre éstas y el Estado. La propia Constitución dedica dos artículos a la distribución de competencias: el 148 se refiere a las competencias que pueden asumir las CCAA en sus respectivos Estatutos y el 149 recoge las competencias sobre las que el Estado se reserva la competencia exclusiva; entre ellas - en el párrafo 1.6- se señala la relativa a la Legislación mercantil. 
Aprovechando la imprecisión existente sobre la calificación y el encuadramiento de la sociedad cooperativa, para la que todavía hay que recurrir al obsoleto artículo 124 del CCom, los Estatutos de Autonomía del País Vasco (art. 10.23) y de Cataluña (art. 9.21) atribuyen a sus CCAA competencia exclusiva en materia de cooperativas. Después, también asumen competencias legislativas exclusivas en esta materia el Estatuto para Andalucía (art. 13.20), el Estatuto de la Comunidad Valenciana (art. 31.21) y la Ley reguladora del Régimen Foral de Navarra (art. 44.7).

El Tribunal Constitucional, a pesar de que fue impugnada la primera Ley vasca de 1982, y que con ella se puso en entredicho la constitucionalidad de toda la delimitación competencial en materia de cooperativas (aunque posiblemente de forma demasiado cautelosa: Paniagua, 1997, 167 y ss.), no contribuye a modificar la situación previamente creada. El recurso se resuelve en la sentencia 72/83, de 29 de julio. De ella se desprende que «las partes centran el debate de la competencia legislativa del País Vasco (y por tanto de las demás Comunidades que han asumido competencia exclusiva) en la consideración del denominado Derecho cooperativo como una parte o no del Derecho mercantil. La trascendencia que otorgan a esta configuración se explica fácilmente porque la $\mathrm{CE}$ establece que el Estado tiene competencia exclusiva en materia de legislación mercantil (art. 149.1.6) y el Estatuto atribuye competencia exclusiva al País Vasco en materia de cooperativas "conforme a la Legislación general en materia mercantil" (art. 10.23), por lo que si la regulación sobre cooperativas hubiera de calificarse de mercantil -como sostiene el Abogado del Estado- la conclusión a la que habríamos de llegar sería la de que la competencia legislativa en materia de cooperativas no corresponde a la Comunidad Autónoma». No obstante, el Tribunal, sin entrar en el fondo del asunto, y sin tener en cuenta que aunque la cooperativa se calificase como sociedad civil la competencia también correspondería al Estado en base al artículo 149.1.8, señala que: «sin pretender ahora sentar afirmaciones de carácter general [...] si podemos afirmar que en principio no es admisible una interpretación que conduzca a variar de contenido la competencia legislativa de la Comunidad en materia de cooperativas, que hay que entender le viene atribuida por el artículo 10.23 del Estatuto». A esta conclusión «conduce la interpretación sistemática de los preceptos de la Constitución y del Estatuto, situado en el marco constitucional, y que prescinde de cualquier posición doctrinal acerca de si las cooperativas han de calificarse o no como sociedades mercantiles, ya que la interpretación ha de situarse en el contexto del ordenamiento vigente» (Fundamento jurídico $3^{\circ}$ ). 
En principio, sólo las cinco Comunidades referidas asumieron competencia legislativa exclusiva, aunque, en la actualidad, todas las CCAA tienen transferida la competencia en la materia. Como resultado de los Acuerdos Autonómicos suscritos por los dos partidos mayoritarios en febrero de 1992, se transfirió la competencia exclusiva sobre cooperativas a las CCAA del art. 143 (art. 2 letra c) LO 9/1992, de 23 de diciembre): Asturias, Cantabria, La Rioja, Murcia, Aragón, Extremadura, Baleares, Madrid, Castilla- La Mancha y Castilla- León. Galicia recibe la transferencia a través de la Ley Orgánica 16/95, de 27 de diciembre, y, finalmente, Canarias asume la competencia en la reforma estatutaria realizada mediante la Ley Orgánica 4/96, de 30 de diciembre.

Como consecuencia de esta delimitación material de competencias en materia de cooperativas, nos encontramos, de un lado, con una Ley 27/1999 de cooperativas (LCoop), que sustituye a la Ley 3/1987 (LGC), que se aplicará en aquellas CCAA que no han aprobado ley de cooperativas y de forma supletoria en las Comunidades con norma propia; y de otro, con las leyes propias de las Comunidades que las han aprobado: Ley 4/93 de cooperativas del País Vasco (LCPV), que deroga la anterior Ley 1/1982; Ley 18/ 2002 de cooperativas de Cataluña (LCCat), que sustituye al Texto Refundido aprobado por Decreto Legislativo 1/1992; Ley 2/1999, modificada en 2002, de sociedades cooperativas andaluzas (LCAnd), que sustituye a la Ley 2/1985; Ley 8/2003 de cooperativas de la Comunidad valenciana (LCCV), que deroga el Texto Refundido aprobado por el Decreto Legislativo 1/1998; Ley Foral 12/2002 de cooperativas de Navarra (LFCN), que sustituye a la derogada Ley 12/1996; Ley 2/1998 de sociedades cooperativas de Extremadura (LCEEx); Ley 9/1998 de sociedades cooperativas de Aragón (LCAr); Ley 5/1998 de cooperativas de Galicia (LCG); Ley 4/1999 de cooperativas de la Comunidad de Madrid (LCCM); Ley 4/2001 de cooperativas de la Rioja (LCLR); Ley 20/2002 de cooperativas de Castilla-La Mancha (LCCLM); Ley 4/2002 reguladoras de las cooperativas de Castilla y León (LCCL); la Ley 1/2003 de cooperativas de las Islas Baleares (LCIB); la Ley 8/2006 de cooperativas de la Región de Murcia (LCMur); y Ley 4/2010 de cooperativas del Principado de Asturias (LCAstur.)

El origen de la compleja y criticable situación legislativa del Derecho Cooperativo Español, con casi una Ley por cada Comunidad Autónoma, se debe achacar, entre otras circunstancias, a la pasividad del Gobierno central respecto a las cooperativas, frente a la actitud muy activa de ciertas Comunidades Autónomas (especialmente la vasca y catalana con 
una mayor tradición cooperativa), y a la labor ciertamente permisiva del TC a la hora de enjuiciar la competencia legislativa de las Comunidades Autónomas en esta materia. A todo esto contribuyeron determinados pactos políticos, que alejan el argumento jurídico inicialmente esgrimido de la no mercantilidad de las cooperativas para la atribución de competencias legislativas a las Comunidades Autónomas (Vicent Chuliá, 1979, p. 131). Hay que recordar que el Estado también tiene competencia exclusiva en la legislación civil, sin perjuicio de la conservación, modificación y desarrollo por las Comunidades Autónomas de los Derechos forales o especiales — art. 149.1.8. ${ }^{a} \mathrm{CE}$-, obstáculo para la legitimación legislativa autonómica que se intentó salvar alegando de modo, en nuestra opinión, poco consistente el carácter autónomo del Derecho cooperativo. A este respecto, nos parece que no se le ha dado toda la importancia que debía al carácter mercantil de la gran mayoría de sociedades cooperativas.

A la hora de valorar esta situación encontramos serios recelos. La doctrina de forma mayoritaria (Arroyo, Borjabad, Divar, Vicent Chuliá, Paniagua, etc.) coincide en que la fragmentación de nuestra Legislación cooperativa es perjudicial para una sociedad que tiene que competir con instituciones capitalistas que tienen una regulación uniforme y difícilmente explicable ante el mandato de fomentar las sociedades cooperativas que impone el artículo 129.2 de la CE. E, igualmente, en que la existencia de tantas leyes de cooperativas en España va en contra de la propia lógica jurídica. Es comúnmente aceptado que las CCAA, en materia de cooperativas, no necesitan regular ex novo y totalmente todo lo relativo a las mismas. Ciertamente, no se ve ninguna necesidad de que materias como el concepto legal de sociedad cooperativa, el régimen de los órganos de gestión y control de la cooperativa y de verificación o censura de cuentas, el régimen del capital, las causas de disolución o el procedimiento de liquidación sean distintas en cada uno de los territorios autónomos. Aún adquiere más consistencia este argumento cuando es opinión comúnmente aceptada que tampoco es conveniente que existan diferencias en relación con los aspectos citados entre la Legislación italiana, alemana o francesa, por lo que sería conveniente que se publicase una Directiva en orden a uniformar el Derecho de cooperativas, como se ha hecho con el Derecho de sociedades de capital en sus aspectos más importantes (Vicent Chuliá, 1976, pp. 81 y s.).

Esta situación legislativa, de difícil marcha atrás, podría haberse evitado si cuando se plantea el tema competencial se hubiese seguido la orientación doctrinal que, convencida del grave perjuicio que el divorcio entre las cooperativas y el Derecho mercantil ha tenido para 
aquéllas, reclamaba que se les aplicase el régimen jurídico de la organización de la empresa económica: el régimen jurídico mercantil (Polo, 1978, pp. 578 y ss.).

Es indudable que este momento se perdió una gran oportunidad para remediar el deficiente tratamiento anterior y para adoptar una postura más coherente sobre el futuro modelo de la legislación sobre cooperativas (Gadea, 2000, p. 256). Ahora, desde una postura realista, no puede negarse que conseguir la armonización no es fácil, y menos por el cauce del art. 150.3 de la CE, debido al coste político que conlleva (Paniagua, 2005, p. 200).

\subsubsection{Referencia a las Leyes de Cooperativas publicadas después de la Constitución}

En nuestro país la etapa inmediatamente posterior a la promulgación de la Constitución no supone un avance en el objetivo de perfeccionar la regulación de las sociedades cooperativas. El Proyecto de Ley general de 1980, la Ley vasca de 1982 y la Ley catalana de 1983, desde este punto de vista, no superan la Legislación que, tras años de espera, consigue confeccionarse en 1978.

La modificación de la normativa anterior era necesaria; la Ley de 1974 partía de presupuestos políticos diferentes y, además, debían publicarse las nuevas Leyes autonómicas. No obstante, resulta difícil entender, no tanto en el caso de las Comunidades Autónomas, pero sí con relación al Proyecto de Ley general, que no se tomasen como punto de partida las disposiciones anteriores que (sin perjuicio de que fuese necesario corregir defectos y recoger las innovaciones inspiradas en los resultados obtenidos de la observación de la evolución cooperativista) supusieron (considerando tanto la Ley como el Reglamento aprobado en 1978) un perfeccionamiento muy importante en la regulación de la sociedad cooperativa

En relación con las dos primeras Leyes autonómicas debemos señalar que, en su elaboración, renace el clásico prejuicio extramercantilista motivado, no ya por razones de "puridad cooperativista", sino ante el peligro de pérdida de la competencia sobre la base del artículo 149.1.6 de la Constitución. La impugnación de la Ley vasca origina el dictamen del Consejo Consultivo de la Generalidad de Cataluña en relación con el Proyecto de Ley de cooperativas (BOPC de 3 de Mayo de 1982) donde resulta curioso observar como se define el Derecho mercantil en su sentido más estricto, el contenido en el Código de comercio y en sus Leyes complementarias, se intenta delimitar la sociedad cooperativa haciendo especial 
hincapié en que persigue una finalidad de carácter social (de ayuda mutua y equitativa de todos los miembros, con un criterio esencial de reciprocidad) y se desaconseja la aplicación a las sociedades cooperativas de aquellas soluciones que pueden ser consideradas como materia mercantil. Es significativo en este sentido, el tratamiento que realizan las Leyes citadas sobre la constitución de la sociedad (sobre todo en la Ley vasca) y el tema registral en que se suprime toda alusión al Registro Mercantil (en contra de lo dispuesto por las Legislaciones de la mayoría de los países de nuestro entorno) por las connotaciones que ello implica.

Sin embargo, posteriormente, una vez delimitadas las competencias en la materia y ante la postura flexible del Gobierno central, los legisladores vasco y catalán han actualizado su regulación. En el caso catalán a través de las diferentes reformas que originan el texto actual de 2002 y en el vasco, fundamentalmente, a través de la publicación de la nueva Ley de 1993.

En las demás Leyes autonómicas podemos observar que desaparece, en gran medida, el perjuicio anteriormente señalado. A la hora de valorarlas algunas de ellas señalaremos que la Ley andaluza es, en general, escasamente innovadora a pesar de haber sido impugnada en dos normas concretas; en materia de Seguridad social y en materia de operaciones con terceros en las cooperativas de crédito (artículo 99); de la Ley valenciana debe destacarse su nivel técnico, incluso ha incluido materias discutidas a nivel de competencia constitucional como los principios de publicidad material en el orden registral (que posteriormente han sido incorporados por otras normas) aunque, a nuestro juicio, tiene como defecto el que parte de un enfoque restrictivo y clasista en relación con el Cooperativismo; la primera Ley navarra (publicada con posterioridad a la Ley general) podía ser valorada con mayor flexibilidad si hubiese sido publicada en 1982 pero teniendo en cuenta su fecha de promulgación debe señalarse que en muchos aspectos partía de planteamientos superados $\mathrm{y}$, por tanto, era necesaria su reforma. En la vigente se introducen mejoras técnicas, aunque, a pesar de ello, sigue sin ser una Ley especialmente innovadora ni destacable por su nivel técnico. Por último, en la Ley extremeña se aprecia que se han estudiado a fondo las diferentes normas ya existentes, para, así, intentar implantar un régimen adecuado. Incluso, establece figuras novedosas como las sociedades cooperativas especiales (artículo 69), en las que se flexibiliza el régimen legal ordinario para favorecer la consolidación de proyectos empresariales bajo la formula cooperativa. No obstante, es criticable que todavía se permita -artículo 36.2- ampliar los supuestos de competencia de la asamblea a todos los asuntos en que así se disponga en los 
estatutos cuando es plenamente aceptado en el ámbito cooperativo que el consejo rector debe conformarse como el órgano de gobierno, representación y gestión de la cooperativa con carácter exclusivo y excluyente. Según nuestro criterio, en ese mismo defecto incurre la Ley de la Comunidad de Madrid.

De la primera Ley general publicada después de 1978, la doctrina destaca y critica su dilatada elaboración para la que han sido confeccionados dos Proyectos de Ley (el de 1980 y el de 1985). Este hecho ha invertido el orden lógico del proceso, que debiera haber comenzado con la Ley general. Sin embargo, como consecuencia de ello es una Ley reflexionada tanto por el largo periodo dedicado a su estudio como porque ha podido ponderar las ventajas e inconvenientes de las soluciones incorporadas a las Leyes autonómicas; por ello en aspectos concretos mejora y cubre las lagunas dejadas por las otras normas. La vigente Ley (general) 27/1999, de 16 de julio, de Cooperativas nace con dos objetivos fundamentales:

$1^{\circ}$. Para definir el ámbito de aplicación de la normativa estatal, que en la práctica ha sido ampliamente reformulado al asumir las Comunidades Autónomas la competencia exclusiva en materia de cooperativas.

$2^{\circ}$. Para incorporar los cambios legislativos que se han producido tanto en el ámbito nacional como en el comunitario. En efecto, como reconoce la propia exposición de motivos: "desde 1989, buena parte del Derecho de sociedades ha sido modificado para adaptarlo a las Directivas europeas sobre la materia. Con ello, se han introducido algunas novedosas regulaciones que parece muy conveniente incorporar también a la legislación cooperativa, como las que afectan, entre otras, a la publicidad societaria, al depósito de cuentas anuales, a las transformaciones y fusiones, a las competencias de los órganos de administración y a los derechos y obligaciones de los socios".

A nuestro juicio, debe ser destacada, por haber sido, además, referencia para las otras normas, la Ley 4/93, de 24 de Junio, de Cooperativas del País Vasco. Esta norma contiene una regulación técnica y adecuada de las sociedades cooperativas, para lo que se ha tenido presente la reforma del Derecho mercantil en general y del Derecho societario en particular, para su adaptación a las Directivas de la CEE. Esta nueva regulación pretende ofrecer los instrumentos necesarios, no sólo para que las sociedades cooperativas puedan superar una etapa de crisis, sino para que la organización cooperativista pueda ocupar un papel relevante dentro de la actividad económica. Para afrontar este reto es necesario que las cooperativas 
puedan reforzar sus recursos financieros, actuar en cualquier campo económico, contraer las oportunas alianzas y tener acceso a las superestructuras que puedan competir con las otras ya establecidas. Se trata de eliminar las trabas jurídicas existentes para que las cooperativas puedan actuar en el mercado con idénticas posibilidades que el resto de las empresas con las que deben competir. Por ello, la reforma supone la desviación del modelo clásico de sociedad cooperativa y la creación de un tipo societario que, en lo externo, se acerca a una organización tipo sociedad lucrativa. Se ha regulado un modelo de "Cooperativismo remodelado" para que las sociedades cooperativas consigan sus objetivos en un mercado de feroces rivalidades, aunque sin renunciar a la puridad de sus principios y singularmente a la solidaridad y los fines sociales (Divar, 1985, p. 48).

El futuro exige redactar normas que diseñen un modelo de cooperativa abierto, atractivo (desde el punto de vista de sus utilidades) y acorde con los nuevos tiempos. Es básico el desarrollo del cooperativismo de base funcional o economicista. De no optarse decididamente por la apertura, el modelo cooperativo quedará condenado a una condición marginal, en beneficio de las opciones verdaderamente capitalistas.

Recientemente, y con el objeto señalado de establecer un marco normativo mercantil y administrativo capaz de estimular la actividad empresarial y mejorar la posición competitiva de las pequeñas y medianas cooperativas en el mercado, también se ha aprobado la Ley 6/2008, de 25 de junio, de la Sociedad Cooperativa Pequeña del País Vasco (anteriormente, con un objetivo similar, ya se había publicado la Ley 8/2006, de 23 de diciembre, de Sociedades Cooperativas especiales de Extremadura). En esta norma, con la que se pretende dar respuesta a las cooperativas de trabajo asociado que no superen el número de diez personas socias trabajadoras, se contempla la reducción a dos del número mínimo de personas para crear una empresa cooperativa; se simplifican los trámites para la constitución e inscripción de nuevas iniciativas empresariales; y se flexibiliza la contratación de trabajadores por cuenta ajena o socios de duración determinada hasta la consolidación de la nueva empresa. 


\section{BIBLIOGRAFÍA}

ALTHAUS, A.: Tratado de Derecho cooperativo, $2^{\text {a }}$ ed., Zeus, 1977, Rosario.

ASCARELLI, T.: Cooperative e società. Concettualismo giuridico e magia delle parole, Rivista delle Società, 1957, pp. 415 y ss.

ASCARELLI, T.: Società, associazione, consorzi, coooperative, en Studi in tema di società, Milán, Giuffrè, 1952, pp. 402 y ss.

ASCARELLI, T.: Iniciación al estudio del Derecho mercantil, 1964, Barcelona, Bosch.

BASSI, A.: Cooperazione e mutualità. Contributo allo studio della cooperativa di consumo, 1976, Nápoles.

BASSI, A.: Delle imprese cooperative e delle mutue assicuratrici, en Il Codice civile: Comentario, Dir. SCHLESINGER, Giuffré, 1988, Milán.

BASSI, A.: Le società cooperative, UTET, 1995, Turín.

BENAVIDES, D.: Evolución del Pensamiento Cooperativo, 1987, Buenos Aires.

BIAGI, M.: Cooperative e rapporti di lavoro, Ed. Franco Angeli, 1983, Milán

BOLAFFI, G.: La società semplice. Contributo alla teoria delle società di persone, Giuffrè (reimp. 1974), 1947, Milán.

BONFANTE, G.: Imprese cooperative, en Commentario del Codice Civile Scialoja-Branca, Dir. GALGANO, Zanicheli, 1999, Bolonia.

BORJABAD, P.: Manual de Derecho Cooperativo General y Catalán, Bosch, 1993, Barcelona.

BRUNETTI, A.: Tratado del Derecho de las sociedades, T. III, 1960, Buenos Aires.

BUONOCORE, V.: Diritto de la cooperazione, Il Mulino, 1997, Bolonia.

COUTANT, L.: L'evolution du Droit coopératif de ses origines a 1950, 1950, Reims.

DEL ARCO, J.L.: Ordenación jurídica de la cooperación en España, Anales de Moral social y económica, Vol. 3, 1963, pp. 248 y ss.

DEL ARCO, J.L.: El nuevo Reglamento de Cooperación, 1972, Zaragoza.

DIVAR, J.: La alternativa Cooperativa, CEAC , 1985, Barcelona.

DIVAR, J.: Régimen jurídico de las sociedades cooperativas, Universidad de Deusto, 1987, Bilbao.

DIVAR, J.: La Democracia económica, Universidad de Deusto, 1990, Bilbao.

DIVAR, J.: Análisis del poder económico, Universidad de Deusto, 1991, Bilbao.

DIVAR, J.: Globalización y democracia, Dykinson, 2005, Madrid. 
DIVAR, J. Y GADEA, E.: Adaptación de la Ley de Cooperativas del País Vasco a las Normas Internacionales de Contabilidad (Apuntes para una nueva configuración del régimen del capital en las Sociedades Cooperativas), REVESCO, núm. 89, 2006, pp. 7-26.

DIVAR, J. Y GADEA, E.: Desarrollo territorial, participación y cooperativismo, REVESCO, núm. 92, 2007, pp. 132-152.

DRIMER A. Y B.: Las Cooperativas. Fundamento, historia y doctrina, 1981, Buenos Aires.

FAUQUET, G.: Il settore cooperativo, 1948, Milán.

FERRARA, F. Y CORSI, F.: Gli imprenditori e le società, 1992, Milán.

FERRI, E.: La cooperativa como società, Riv. Soc., I, 1957, pp. 249- 262.

FERRI, E.: Le società, UTET, 3 ed, 1987, Torino.

GADEA SOLER, E.: Análisis histórico-legislativo en torno a la Sociedad Cooperativa, AEC, 1994, pp. 101-198.

GADEA SOLER, E.: Evolución de la Legislación Cooperativa en España, Ed. por el Consejo Superior de Cooperativas del País Vasco, 1999, Vitoria.

GADEA SOLER, E.: Derecho de las Cooperativas (Análisis de la Ley 4/1993, de 24 de junio, de Cooperativas del País Vasco), Universidad de Deusto, $2^{\text {a }}$ Ed, 2000.

GALGANO, F.: La società per azioni. Le altre società di capitali. Le cooperative, Zanichelli, 3. ${ }^{\mathrm{a}}$ ed, 1970, Bolonia.

GARRIDO DE PALMA, M.: La Cooperativa en el Derecho español a través de sus principios, en Rev. Dere. Not., 1981, pp. 12 y ss.

HOLYOAKE, J.: Historia de los Pioneros de Rochdale, 1973, Zaragoza.

LAMBERT, P.: La Doctrina cooperativa, INTERCOOP, 1970, Buenos Aires.

LLOBREGAT HURTADO, M. ${ }^{a}$ L.: Mutualidad y empresa cooperativas, Bosch, 1990, Barcelona.

LUCAS FERNÁNDEZ, F.: Nacimiento jurídico de la cooperativa, Tribuna Cooperativa, núm. 14, 1973, pp. 9 y ss.

MARTÍNEZ CHARTERINA, A.: Análisis de la integración cooperativa, Universidad de Deusto, 1990, Bilbao.

OPPO, G.: L'essenza della societá cooperativa e gli estudi resentí, Rivista di diritto civile, I, 1959, pp. 392 y ss.

OPPO, G.: La nuova legislazione commerciale, Rivista di Diritto Civile, núm. 2, 1999, pp. 359 y ss.

PANIAGUA ZURERA, M.: Mutualidad y lucro en la sociedad cooperativa, MacGraw-Hill, 1997, Madrid.

REVESCO No 108 - Segundo Cuatrimestre 2012 - ISSN: 1885-8031 - www.ucm.es/info/revesco 
PANIAGUA ZURERA, M.: La sociedad cooperativa. Las sociedades mutuas de seguros y las mutualidades de previsión social, Vol. 1, Tomo XXII del Tratado de Derecho mercantil, Coord. JiMÉNEZ SÁNCHEZ, Marcial Pons, 2005, Madrid.

PANIAGUA ZURERA, M.: La determinación y la distribución de los resultados del ejercicio económico en la sociedad cooperativa: propuestas de armonización legislativa, $R d S$, núm. 25, 2005, p. 199-229.

PANIAGUA ZURERA, M.: El estatuto de la sociedad cooperativa Europea: el problema de su aplicación en España, La Sociedad Cooperativa, núm. 34, 2007, pp. 19-23.

POLO, E.: Notas al Tratado de Derecho mercantil de CosACK, (trad. POLO), Ed. RDP, 1935, Madrid.

POLO, E.: Misión y sentido de la nueva Ley de Cooperación, Ed. RDP, 1942, Madrid.

POLO, E.: Leyes mercantiles y económicas, Ed. RDP, 1950, Madrid.

POLO, E.: Reflexiones sobre la reforma del ordenamiento jurídico mercantil, en Estudios de Derecho mercantil en Homenaje a Rodrigo Uria, 1978, Madrid.

SÁNCHEZ CALERO, F.: La determinación y distribución del beneficio neto en la Sociedad Anónima, 1955, Roma-Madrid.

SÁNCHEZ CALERO, F.: Los conceptos de sociedad y empresa en la Ley de cooperativas, en Libro homenaje a Roca Sastre, T. III, 1977, Madrid, pp. 493- 524.

SÁNCHEZ CALERO, F. Y OLIVENCIA, M.: Relaciones del régimen jurídico de las sociedades mercantiles y de las sociedades cooperativas, Anales de Moral social y económica, Vol. 6, 1964.

SIMONETO, E.: Il lucro dell impresa cooperativa, utile e risparmio di spesa, Riv. Delle Soc., 1970, pp. 237 y ss.

SOLDEVILLA VILLAR, A.: El movimiento cooperativista mundial, Impr. Talleres Gráficos Ceres, 1973, Valladolid.

VARGAS VASSEROT, C.: La actividad cooperativizada y las relaciones de la cooperativa con sus socios y con terceros, Monografía asociada a la RdS (núm. 27), ThomsonAranzadi, Premio Arco Iris del Cooperativismo a la Mejor Investigación Cooperativa (XVI edición), 2006, Pamplona.

VÉRGEZ SÁNCHEZ, M.A.: El Derecho de las cooperativas y su reforma, Civitas, 1973, Madrid.

VERRUCOLI, P.: La società cooperativa, Giuffrè, 1958, Milán.

VERRUCOLI, P.: Voz Cooperative (Imprese), en Enciclopedia del diritto, 1962, Milano, pp. 548 a 608. 
VERRUCOLI, P.: Tendencias sobre Derecho comparado Europeo sobre cooperación, Anales de Moral social y económica, Centro de Estudios de la Santa Cruz del Valle de los Caídos, Vol. 9, 1965.

VICENT CHULIÁ, F.: Análisis crítico del nuevo Reglamento de Cooperación (Decreto 2396/1971 de 13 de agosto, B.O.E. de 9 de octubre), RDM, núm. 20, 1972, pp. 429 - 537.

VICENT CHULIÁ, F.: El régimen económico de la cooperativa en la Ley de 19 de diciembre de 1974, REVESCO, núms. 36-38, 1974, pp. 162 y ss.

VICENT CHULIÁ, F.: Las empresas mutualísticas y el Derecho mercantil en el Ordenamiento español, $R C D I$, núm. 21, 1976, pp. 68-132.

VICENT CHULIÁ, F.: El accidentado desarrollo de nuestra legislación cooperativa, Revista Jurídica de Cataluña, núm. 4, 1979, pp. 107 - 144.

VICENT CHULIÁ, F.: Ley General de cooperativas, T. XX, Vol. 1. (artículos 1 a 28), con Paz CANalejo en Comentarios al Código de Comercio y Legislación mercantil especial, Dir. SÁnchez CALERo/AlbaladeJo, EDERSA, 1989, Madrid.

VICENT CHULIÁ, F.: Ley General de cooperativas, T. XX, Vol. 2. ${ }^{\circ}$ (artículos 29 a 66), con Paz Canalejo en Comentarios al Código de Comercio y Legislación mercantil especial, Dir. SÁnchez CAlero/AlbaladeJo, EDERSA, 1990, Madrid.

VICENT CHULIÁ, F.: Ley General de cooperativas, T. XX, Vol. 3. ${ }^{\circ}$ (artículos 67 al final), con Paz Canalejo en Comentarios al Código de Comercio y Legislación mercantil especial, Dir. SÁnchez CALERO/AlbaladeJo, EDERSA, 1994, Madrid.

VIVANTE, C.: Trattato di Diritto commerciale, Vol. II, 1932, Milán, 5. ed. 